\title{
Expression and roles of lumican in lung adenocarcinoma and squamous cell carcinoma
}

\author{
YOKO MATSUDA ${ }^{1}$, TETSUSHI YAMAMOTO ${ }^{1}$, MITSUHIRO KUDO ${ }^{1}$, KIYOKO KAWAHARA $^{1}$, \\ MASASHI KAWAMOTO ${ }^{1,2}$, YUKI NAKAJIMA ${ }^{3}$, KIYOSHI KOIZUMI ${ }^{3}$, \\ NANDO NAKAZAWA ${ }^{1}$, TOSHIYUKI ISHIWATA ${ }^{1}$ and ZENYA NAITO ${ }^{1}$
}

\author{
${ }^{1}$ Department of Pathology, ${ }^{2}$ Division of Clinical Pathology and ${ }^{3}$ Department of Surgery, Division of Thoracic Surgery, \\ Nippon Medical School, 1-1-5 Sendagi, Bunkyo-ku, Tokyo 113-8603, Japan
}

Received August 4, 2008; Accepted October 1, 2008

DOI: 10.3892/ijo_00000107

\begin{abstract}
Lumican is a member of a small leucine-rich proteoglycan family and is highly expressed in several types of cancer cells and/or stromal tissue. Lumican expression in the cytoplasm in advanced colorectal cancer correlates with poor patient prognosis. The expression of lumican in stromal tissues is associated with a high tumor grade, a low estrogen receptor expression level, and young age in breast cancer and is associated with tumor invasion and advanced stage in pancreatic cancer. In this study, we examined the expression and role of lumican in lung cancer including adenocarcinoma (ADC) and squamous cell carcinoma (SqCC). Immunohistochemically, lumican was weakly expressed in vascular smooth muscle cells, perivascular and peribronchial connective tissues and bronchial epithelium of normal lung tissues. In lung cancer tissues, lumican was localized in the cytoplasm of cancer cells and/or stromal tissues adjacent to cancer cells. In ADC, the expression level of lumican in cancer cells correlated with pleural invasion and larger tumor size, but that of lumican in stromal tissues did not correlate with clinicopathological factors. In SqCC, the expression level of lumican in cancer cells correlated with formation of a keratinized pattern, and stromal lumican expression correlated with vascular invasion. In $\mathrm{SqCC}$ and $\mathrm{ADC}$, the expression level of lumican in cancer cells did not correlate with patient prognosis. In lung cancer cell lines, lumican mRNA and protein were expressed in LC-1/ $\mathrm{Sq}$ and EBC-1 cells established from SqCC, and A549, RERF-LC-KJ and PC-3 cells from ADC. The molecular weight of lumican extracted from the cytoplasm of lung cancer cells differed from that in the culture medium owing to glycosylation of the protein. These findings suggest that the
\end{abstract}

Correspondence to: Dr Zenya Naito, Department of Pathology, Integrative Oncological Pathology, Nippon Medical School, 1-1-5 Sendagi, Bunkyo-ku, Tokyo 113-8602, Japan

E-mail: naito@nms.ac.jp

Key words: lumican, proteoglycan, lung, adenocarcinoma, squamous cell carcinoma expression pattern and the glycosylated type of lumican in cells and stromal tissues correlate with the aggressiveness of lung SqCC and ADC.

\section{Introduction}

Lumican is a member of the small leucine-rich proteoglycan (SLRP) family. SLRP family members have small core proteins of $\sim 40 \mathrm{kDa}$ and possess 6-10 leucine-rich repeating units flanked by disulfide-bonded domains and glycosaminoglycan side chains (1-3). The SLRP family was reported to regulate the extracellular matrix function such as tissue hydration and collagen fibrillogenesis. Furthermore, SLRP proteins modulate cell migration and proliferation during embryonic development, tissue repair and tumor growth. Lumican is the major keratan sulfate proteoglycan of the cornea, and was reported to colocalize with fibrillar collagen and regulate the assembly and diameter of collagen fibers (4-6). Lumican is also distributed in interstitial collagenous matrices in the skin, pancreas, intervertebral disks, skeletal muscle, kidneys, intestine, brain, placenta, heart, aorta, liver and lungs $(3,7-12)$. Mice that are homozygous for the null mutation in lumican show corneal opacification and skin laxity owing to heterogeneous collagen bundles (5).

In breast cancer tissues, a high expression level of lumican in the stromal tissue is associated with a high tumor grade, a low estrogen receptor (ER) expression level and young age (13). We previously reported prominent lumican expression in stromal tissues adjacent to colorectal, uterine cervical and pancreatic cancer cells $(12,14-19)$. In pancreatic cancer, lumican expression in stromal tissues correlates with female gender, advanced stage, retroperitoneal and duodenal invasion and residual tumor (18). Patients with lumican-positive pancreatic cancer cells tend to have a higher survive rate than those with lumican-negative cancer cells, but patients with lumican-positive stromal tissues show a reduced survival compared to those with lumican-negative stromal tissues. These findings suggest that the presence of lumican in stromal tissues, adjacent to cancer cells, plays important roles in cancer cell growth.

Non-small cell lung carcinoma often causes fibrosis, scarring, or hyalinization close to a cancer cell nest. In lung adenocarcinoma (ADC), the central fibrosis or scar grade has 
been reported as an important prognostic factor (20-24), whereas its prognostic importance has not been confirmed in lung squamous cell carcinoma (SqCC) $(25,26)$. Fibrous tissues adjacent to cancer cells mainly consist of fibroblasts, collagen fibers, glycoproteins, hyaluronan and proteoglycan and are considered to affect cancer cell proliferation, migration, spread and establishment of metastatic foci (27). The collagenelastin-proteoglycan matrix is the key constituent of lung fibrosis. Although the collagen and elastin components of the lung extracellular matrix have been widely studied $(28,29)$, the exact composition and distribution of the proteoglycan components within the matrix of lungs have not as yet been fully determined.

In human lungs, lumican is a major component of the proteoglycan matrix (7), and lumican has been reported to be involved in airway remodeling of asthma $(30,31)$. The proteomic profiles revealed that 364 protein spots corresponding to 58 gene products, including lumican, were highly expressed in serum from five lung cancer patients (32). However, little is known about the expression and role of lumican in human lung cancer tissues. Therefore, we examined whether lumican is expressed in the cytoplasm and/or stromal tissues of lung $\mathrm{ADC}$ and SqCC. Furthermore, we clarified the correlations of lumican expression in lung $\mathrm{ADC}$ and $\mathrm{SqCC}$ with clinicopathological factors and prognosis.

\section{Materials and methods}

Materials. The following materials were purchased: a Histofine Simple Stain PO (R) Max Kit from Nichirei (Tokyo, Japan); antibiotics and antimycotics from Invitrogen Co. (Carlsbad, CA, USA); Isogen from Nippon Gene Co., Ltd. (Tokyo, Japan); a FastPure RNA Kit from Takara Bio Inc. (Shiga, Japan); a High Capacity cDNA Reverse Transcription Kit from Applied Biosystems (Foster City, CA, USA); a LightCycler TaqMan Master from Roche Diagnostics GmbH (Mannheim, Germany); a goat anti-rabbit IgG-HRP secondary antibody from American Qualex (San Clemente, CA, USA); an IPVH membrane and Immobilon Western Chemiluminescent HRP substrates from Millipore (Yonezawa, Japan); M-PER Mammalian Protein Extraction Reagent from Pierce (Rockford, IL, USA); Ultracel-10K centrifugal filters from Millipore (Billerica, MA, USA); and Human Tissue Microarray 1 from Novagen (Darmstadt, Germany). All other chemicals and reagents were purchased from Sigma Chemical Co. (St. Louis, MO, USA).

Patients and surgical specimens. Lung cancer tissues were obtained from surgical resection specimens $(n=102 ; 51$ for ADC and 51 for SqCC) at Nippon Medical School Hospital (Bunkyo-ku, Tokyo, Japan) from 1997 to 2001. Specimens from patients with interstitial pneumonia, infectious lung disease or other inflammatory lung diseases were excluded from the study. All of the excised tissues were fixed in $10 \%$ neutral-buffered formalin and embedded in paraffin. The sections $(3.5-\mu \mathrm{m})$ were stained with hematoxylin and eosin, and the lung cancer specimens were examined in accordance with the World Health Organization (WHO) histological classification (33). In addition to WHO classification, stromal change was analyzed microscopically, and we divided the lung fibrosis pattern into active fibrosis and sclerosis. In SqCC patients, the degree of keratinization was classified in accordance with the following scale: 0 , no keratinization of cancer cells; I, mild; II, moderate; and III, abundant keratinization. As negative controls, noncancerous tissues, obtained from autopsy $(\mathrm{n}=5)$ and Human Tissue Microarray 1 $(n=1)$ were employed.

The study protocol followed the ethical guidelines of the Nippon Medical School and the principles embodied in the Declaration of Helsinki, 1975.

Immunohistochemical staining of lumican. Lung cancer sections $(n=102)$ obtained from a characteristic lesion in each patient were used for immunohistochemistry using an affinitypurified rabbit anti-lumican polyclonal antibody as previously reported (9). The primary antibody (1:1000 in dilution) was applied to the tissue sections. The sections were then incubated overnight at $4^{\circ} \mathrm{C}$, and then the bound antibodies were detected with Simple Stain PO (R) Max reagents using diaminobenzidine tetrahydrochloride (DAB) as the substrate. Vascular smooth muscle cells (VSMCs) that were positive for lumican in the lung cancer tissue sections were used as an internal positive control (10). For the evaluation of the intensity of lumican staining, the following scale was employed in accordance with a previous report: 0 , no staining; $1+$, mild staining; $2+$, moderate staining; and 3+, intense staining (34). At a magnification of x100, 10 microscopic images, randomly selected for each patient, were analyzed. The average intensity of 10 images was regarded as the lumican index and used for statistical analysis. Staining intensity was determined in the area of the carcinoma cells and stromal tissues adjacent to cancer cells (within $100 \mu \mathrm{m}$ ). For the analysis of survival rate, the average lumican index was calculated, and when the indices were more than the average, patients were designated as lumican-positive. Similarly, the immunohistochemical results for stromal tissues were evaluated to determine positivity or negativity for lumican. Two investigators separately evaluated all the specimens in a blinded manner.

Lung cancer cell lines. SqCC cell lines (LC-1/Sq and EBC-1), and ADC cell lines (A549 and RERF-LC-KJ) were obtained from Riken BioResource Center (Ibaragi, Japan). PC-3, an ADC cell line, was obtained from Health Science Research Resources Bank (Osaka, Japan). The cells were grown in RPMI-1640 medium containing $15 \%$ heat-inactivated fetal bovine serum (FBS), $200 \mathrm{U} / \mathrm{ml}$ penicillin and $200 \mu \mathrm{g} / \mathrm{ml}$ kanamycin at $37^{\circ} \mathrm{C}$ in a humidified $5 \% \mathrm{CO}_{2}$ atmosphere.

Quantitative real-time PCR analysis. Lung cancer cells were grown in RPMI-1640 medium with $15 \%$ FBS for $24 \mathrm{~h}$ and then cultured with serum-free medium for $48 \mathrm{~h}$. Total RNA was extracted from lung cancer cells using Isogen and then purified using a FastPure RNA Kit. Next, cDNA synthesis was performed using a High Capacity cDNA Reverse Transcription Kit following the manufacturer's protocol. Quantitative real-time PCR (Q-PCR) was performed using a LightCycler TaqMan Master System. The real-time PCR primers used for lumican corresponded to nucleotides (nts) 1231-1252 (5'-TGG-AGG-TCA-ATC-AAC-TTG-AGA-A-3') and nts 1302-1322 (5'-CAA-ACG-CAA-ATG-CTTGAT- 


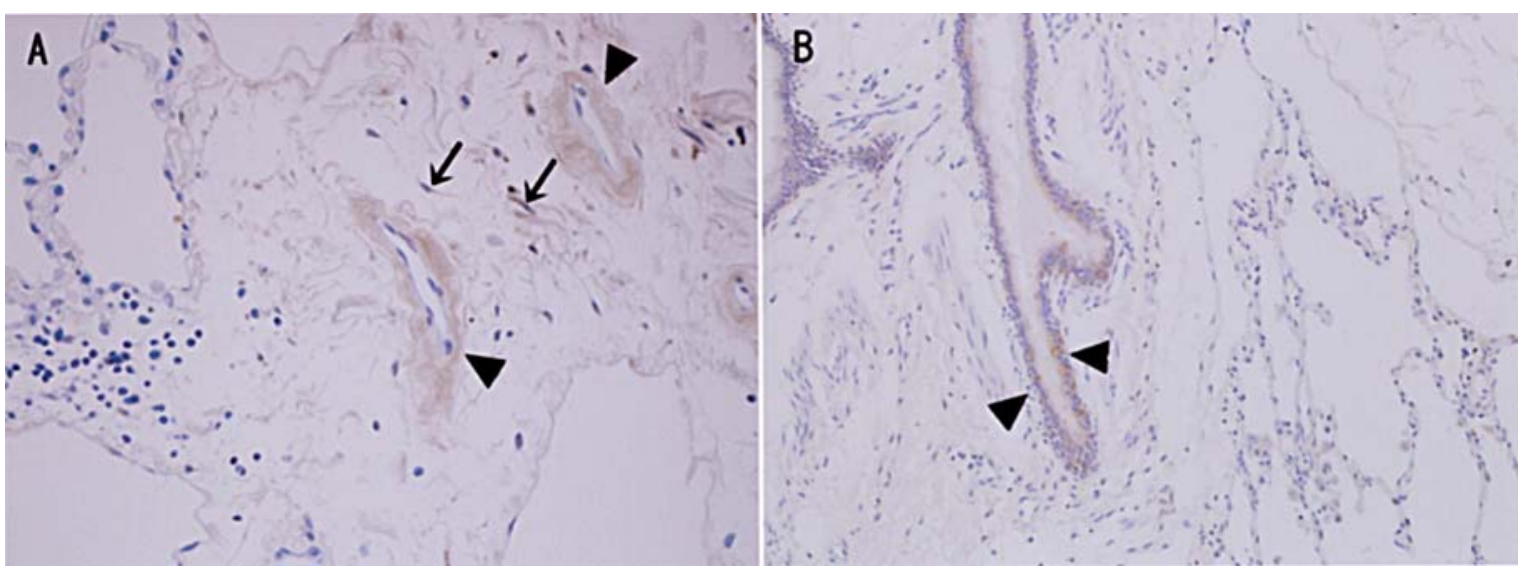

Figure 1. Immunohistochemical analysis of lumican in normal lung tissues. In normal lung tissues, lumican was detected in fibroblasts and collagen fibers in perivascular and peribronchial connective tissues (A, arrows), vascular smooth muscle cells (A, arrowheads), and the bronchial epithelium (B, arrowheads), but not in the alveolar epithelium. Immunohistochemistry. Original magnification: A, x400; B, x200.

CTT-3') (92 bp, Accession no. NM_002345). 18S rRNA, as the internal positive control, was amplified using the following primer pairs: nts 83-103 (5'-TGC-GAG-TACTCA-ACA-CCA-ACA-3') and nts 150-167 (5'-GCA-TATCTTCGG-CCC-ACA-3') (85 bp, Accession no. NM_022551). As TaqMan probes, the Universal ProbeLibrary probe for lumican and 18S rRNA were used (Roche). A PCR reaction mixture containing $2 \mu \mathrm{l}$ of template cDNA, $0.2 \mu \mathrm{M}$ primers, $0.1 \mu \mathrm{M}$ Universal ProbeLibrary probe and $4 \mu 1$ of Light Cycler TaqMan Master Mix was added to a capillary tube. Q-PCR was carried out in the LightCycler, and PCR products were analyzed using LightCycler Data Analysis software ver. 3.5 (Roche). The optimized program involved denaturation at $95^{\circ} \mathrm{C}$ for $10 \mathrm{~min}$, followed by 50 cycles of amplification (at $95^{\circ} \mathrm{C}$ for $10 \mathrm{sec}$ and at $60^{\circ} \mathrm{C}$ for $30 \mathrm{sec}$ ) for lumican and $18 \mathrm{~S}$ rRNA. Results were expressed as target/18S rRNA as an internal standard concentration ratio. The gene expression level was measured in triplicate.

Western blot analysis. Lung cancer cells were grown in RPMI-1640 medium with $15 \%$ FBS for $24 \mathrm{~h}$, and then cultured with serum-free medium for $48 \mathrm{~h}$. Protein was extracted from lung cancer cells in accordance with the protocol for the use of the M-PER Mammalian Protein Extraction reagent. Lysates were centrifuged for $10 \mathrm{~min}$ at $13,000 \mathrm{rpm}$ to pellet cell debris, and the resulting supernatants were collected as intracellular protein. Culture medium $(\sim 30 \mathrm{ml})$ from each cancer cell line was centrifuged for $30 \mathrm{~min}$ at $15,000 \mathrm{rpm}$ to pellet cell debris, and the resulting supernatants were concentrated in Ultracel-10K centrifugal filters to $500 \mu 1$. The concentrations of intracellular protein and the protein in concentrated culture medium were measured by the Bradford method. The cleared protein lysates from the cancer cells and the concentrated culture medium were subjected to sodium dodecyl sulfate-polyacrylamide gel electrophoresis under reducing conditions, and the separated proteins were transferred to Immobilon $\mathrm{P}$ transfer membranes. The membranes were immersed in 5\% skim milk in Tris-buffered saline containing $0.05 \%$ Tween-20 for $60 \mathrm{~min}$ at room temperature and then incubated for $16 \mathrm{~h}$ at $4{ }^{\circ} \mathrm{C}$ with an antilumican antibody (1:800 in dilution). The anti-lumican antibody used was the same antibody employed in immunohistochemical staining. The membranes were washed and incubated with the HRP-conjugated anti-rabbit IgG antibody (1:4000 in dilution) for $60 \mathrm{~min}$. After washing, the blots were visualized using enhanced chemiluminescence and detected with a ChemiDoc XRS System (Bio-Rad Laboratories, Inc., Hercules, CA, USA). To confirm the nearly equal loadings of the proteins from the cancer cells, the membranes were washed and reblotted with an anti- $\beta$-actin antibody. Prior to Western blotting, portions of protein extracts from A549 and LC-1/Sq cells and their concentrated culture medium were chemically deglycosylated using GlycoProfile IV, a chemical deglycosylation kit, in accordance with the manufacturer's protocol.

Statistical analysis. All quantitative data were presented as the mean \pm SD and were assessed using the Student's t-test, the Mann-Whitney test or the Tukey-Kramer test. Furthermore, the degree of keratinization was analyzed using the Spearman rank-order correlation coefficient. The five-year survival rate was assessed using the Kaplan-Meier test. $\mathrm{P}<0.05$ was considered significant in all analyses.

\section{Results}

Immunohistochemical analysis of lumican in lung cancer patients. To confirm the localization of the lumican protein in human lung cancer tissues, immunohistochemical analysis was performed. In normal lung tissues, lumican was expressed in fibroblasts and collagen fibers in perivascular and peribronchial connective tissues (Fig. 1A, arrows), VSMCs (Fig. 1A, arrowheads) and bronchial epithelium (Fig. 1B, arrowheads), but it was not detected in the alveolar epithelium.

In $\mathrm{SqCC}$ and $\mathrm{ADC}$ patients, lumican immunoreactivity was strong in the cytoplasm of carcinoma cells (Fig. 2A and $\mathrm{B}$, respectively) and/or stromal tissues close to the cancer cells (Fig. 2C and D, respectively). We analyzed lumican expression in each type of cancer cell and stromal tissues. The results of immunohistochemical staining of lumican in SqCC and ADC are summarized in Tables I and II, respectively. In $\mathrm{SqCC}$, lumican expression in stromal tissue close to cancer cells significantly correlated with vascular invasion $(\mathrm{p}=0.0316$, 


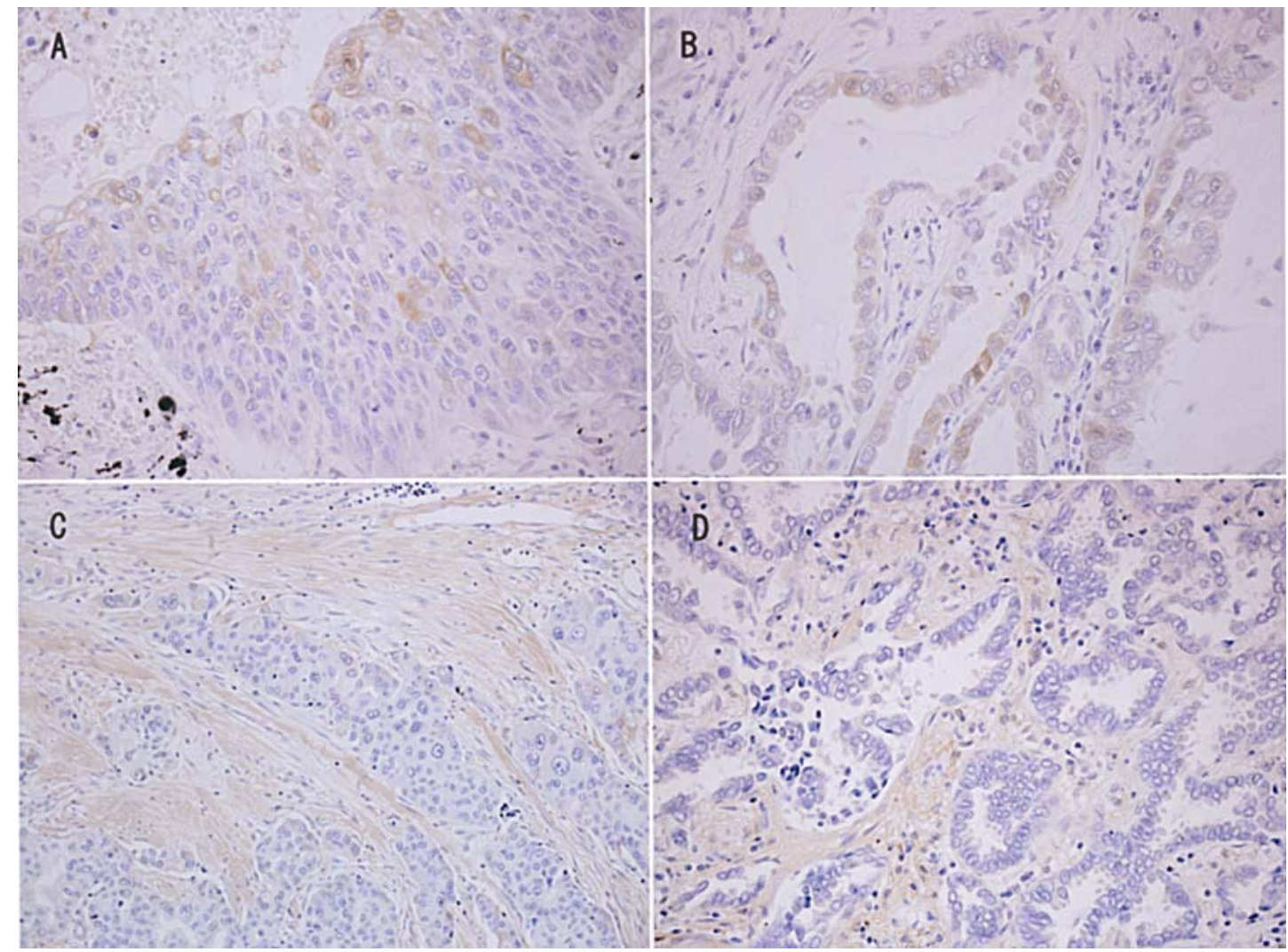

Figure 2. Representative staining patterns of lumican from lung cancer patients. In SqCC, lumican immunoreactivity was detected in the cytoplasm of carcinoma cells and stromal tissues (A and C, respectively). In ADC patients, lumican was localized in the cytoplasm of carcinoma cells and stromal tissues (B and D, respectively). A and C, SqCC patients; B and D, ADC patients. Original magnification, $\mathrm{x} 400$.
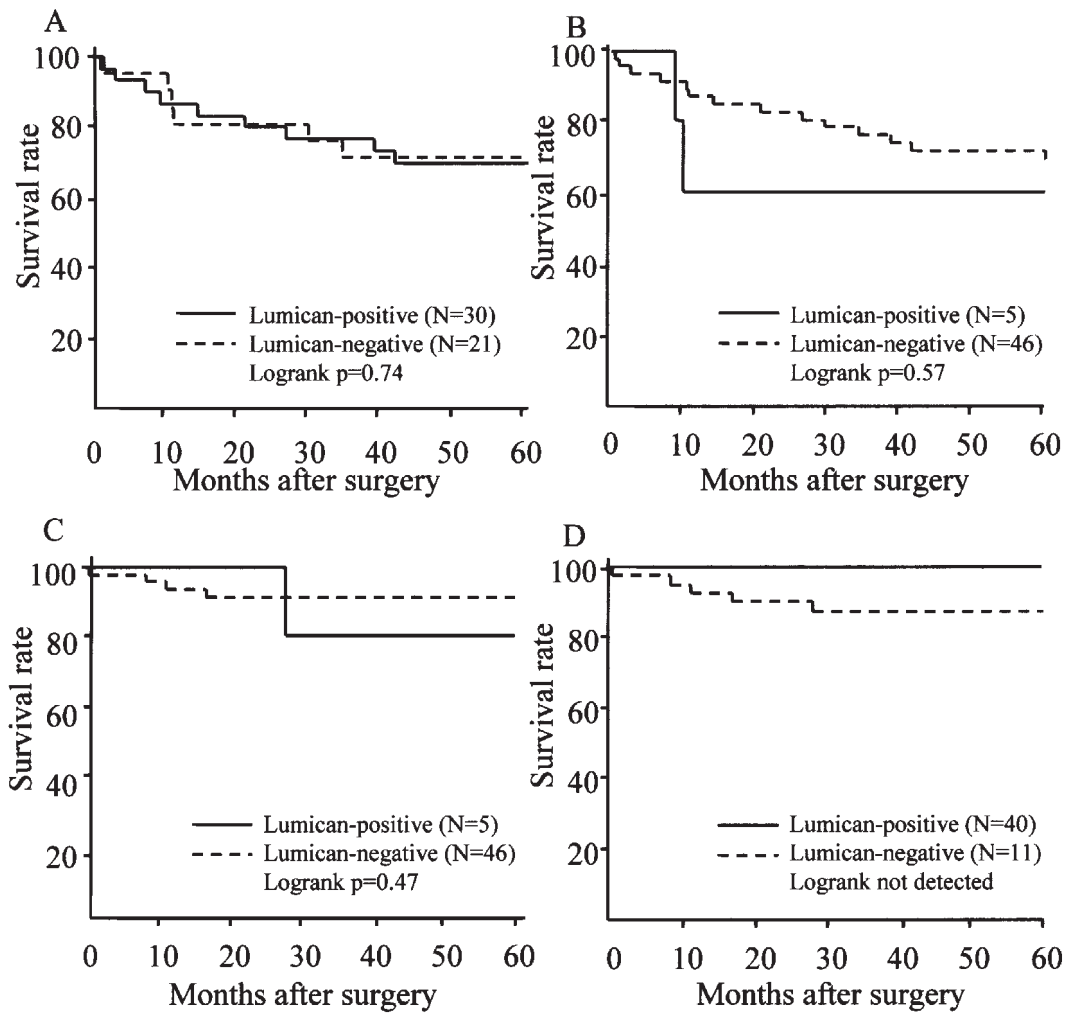

Figure 3. Five-year survival curves of lung carcinoma patients. For the analysis of survival rate, the average lumican index was calculated, and when the lumican indices were more than the average, the patient was designated as lumican-positive. Kaplan-Meier survival curves of lumican-positive and lumicannegative groups of patients for the cytoplasm of SqCC cells (A) and stromal tissues adjacent to SqCC cells (B). Lumican-positive and lumican-negative groups of patients for the cytoplasm of ADC cells (C) and stromal tissues close to ADC cells (D). Lumican expression did not correlate with survival rate in all groups. Continuous line, lumican-positive group; dotted line, lumican-negative group. 
Table I. Immunohistochemistry of lumican in squamous cell carcinoma patients.

\begin{tabular}{|c|c|c|c|c|c|}
\hline & $\begin{array}{l}\text { No. of } \\
\text { patients }\end{array}$ & $\begin{array}{l}\text { Lumican index } \\
\text { of cancer cells }\end{array}$ & P-value & $\begin{array}{l}\text { Lumican index } \\
\text { of stromal tissues }\end{array}$ & P-value \\
\hline Total (age 66.12 \pm 8.18 ) & 51 & $1.75 \pm 1.09$ & & $0.98 \pm 0.51$ & \\
\hline \multicolumn{6}{|l|}{ Gender } \\
\hline Female & 4 & $0.75 \pm 0.96$ & & $1.25 \pm 5.00$ & \\
\hline Male & 47 & $1.83 \pm 1.07$ & 0.0569 & $0.96 \pm 0.46$ & 0.2344 \\
\hline \multicolumn{6}{|l|}{ Differentiation } \\
\hline Well & 13 & $1.92 \pm 1.26$ & & $1.00 \pm 0.41$ & \\
\hline Moderate & 26 & $1.81 \pm 0.98$ & & $0.89 \pm 0.43$ & \\
\hline Poor & 12 & $1.42 \pm 1.17$ & $>0.0500$ & $1.17 \pm 0.58$ & $>0.0500$ \\
\hline \multicolumn{6}{|l|}{ Vascular invasion } \\
\hline- & 23 & $1.70 \pm 1.02$ & & $0.83 \pm 0.39$ & \\
\hline+ & 28 & $1.79 \pm 1.17$ & 0.7729 & $1.11 \pm 0.50$ & $0.0316^{\mathrm{a}}$ \\
\hline \multicolumn{6}{|l|}{ Pleural invasion } \\
\hline- & 28 & $1.68 \pm 1.06$ & & $1.00 \pm 0.39$ & \\
\hline+ & 23 & $1.83 \pm 1.15$ & 0.6362 & $0.96 \pm 0.56$ & 0.7453 \\
\hline \multicolumn{6}{|l|}{ Tumor size } \\
\hline$\leq 30 \mathrm{~mm}$ & 21 & $1.81 \pm 0.98$ & & $0.95 \pm 0.21$ & \\
\hline$>30 \mathrm{~mm}$ & 30 & $1.70 \pm 1.18$ & 0.7284 & $1.00 \pm 0.64$ & 0.7462 \\
\hline \multicolumn{6}{|l|}{ Lymph node metastasis } \\
\hline- & 34 & $1.68 \pm 1.07$ & & $0.97 \pm 0.39$ & \\
\hline+ & 17 & $1.88 \pm 1.17$ & 0.5313 & $1.00 \pm 0.61$ & 0.8351 \\
\hline \multicolumn{6}{|l|}{ Stage } \\
\hline I & 29 & $1.62 \pm 1.05$ & & $0.93 \pm 0.37$ & \\
\hline II & 7 & $2.14 \pm 1.07$ & & $1.00 \pm 0.00$ & \\
\hline III & 14 & $1.93 \pm 1.14$ & & $1.07 \pm 0.73$ & \\
\hline IV & 1 & 0.00 & $>0.0500$ & 1.00 & $>0.0500$ \\
\hline \multicolumn{6}{|l|}{ Stromal change } \\
\hline Active fibrosis & 49 & $1.78 \pm 1.10$ & & $0.98 \pm 0.48$ & \\
\hline Sclerosis & 2 & $1.00 \pm 0.00$ & 0.3301 & $1.00 \pm 0.00$ & 0.9526 \\
\hline \multicolumn{6}{|l|}{ Keratinization } \\
\hline 0 & 14 & $1.14 \pm 1.10$ & & $1.07 \pm 0.62$ & \\
\hline I & 17 & $1.65 \pm 0.93$ & & $1.06 \pm 0.24$ & \\
\hline II & 15 & $2.20 \pm 1.08$ & & $0.80 \pm 0.41$ & \\
\hline III & 5 & $2.40 \pm 0.89$ & $0.0027^{\mathrm{a}}$ & $1.00 \pm 1.00$ & 0.2352 \\
\hline
\end{tabular}

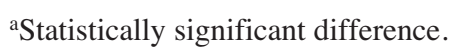

Table I); however expression of lumican in the cytoplasm of SqCC cells showed no significant correlation with vascular invasion $(\mathrm{p}=0.7729)$. Lumican expression in the cytoplasm of SqCC cells correlated with enhancement of keratinization $(\mathrm{p}=0.0027)$. In ADC, expression of lumican in stromal tissues adjacent to cancer cells did not correlate with any clinicopathological features, whereas lumican expression in the cytoplasm of cancer cells correlated with pleural invasion $(\mathrm{p}=0.0123$, Table II) and larger tumor size $(\mathrm{p}=0.0363)$.

SqCC showed higher lumican expression levels in cancer cells than in stromal tissues, whereas ADC showed higher lumican expression levels in stromal tissues than in cancer cells $(\mathrm{p}<0.0001$, respectively). In the comparison between
SqCC and ADC, the expression of lumican in the cytoplasm of SqCC cells showed higher indices than that of ADC cells (SqCC, 1.75 \pm 1.09 and ADC, 0.51 \pm 0.83 ; p <0.0001; Tables I and II). In contrast, stromal lumican expression in SqCC showed lower indices than that in ADC (SqCC, 0.98 \pm 0.51 and ADC, 1.77 $\pm 0.65 ; \mathrm{p}=0.015$; Tables I and II).

The five-year survival rates were $56.5 \%$ in SqCC and $86.5 \%$ in ADC patients. The five-year survival rate was compared between lumican-positive and lumican-negative groups of patients (Fig. 3). In SqCC and ADC, lumicanpositive or lumican-negative groups of patients for cancer cells or stromal tissues showed no significant differences in survival rate (Fig. 3A-D). 
Table II. Immunohistochemistry of lumican in adenocarcinoma patients.

\begin{tabular}{|c|c|c|c|c|c|}
\hline & $\begin{array}{l}\text { No. of } \\
\text { patients }\end{array}$ & $\begin{array}{l}\text { Lumican index } \\
\text { of cancer cells }\end{array}$ & $\mathrm{P}$-value & $\begin{array}{l}\text { Lumican index } \\
\text { of stromal tissues }\end{array}$ & P-value \\
\hline Total (age 63.88 \pm 10.05 ) & 51 & $0.51 \pm 0.83$ & & $1.77 \pm 0.65$ & \\
\hline \multicolumn{6}{|l|}{ Gender } \\
\hline Female & 16 & $0.50 \pm 0.73$ & & $1.75 \pm 0.58$ & \\
\hline Male & 35 & $0.46 \pm 0.89$ & 0.8667 & $1.77 \pm 0.69$ & 0.9144 \\
\hline \multicolumn{6}{|l|}{ Differentiation } \\
\hline Well & 34 & $0.62 \pm 0.92$ & & $1.82 \pm 0.63$ & \\
\hline Moderate & 11 & $0.27 \pm 0.65$ & & $1.55 \pm 0.82$ & \\
\hline Poor & 6 & $0.00 \pm 0.00$ & $>0.0500$ & $1.83 \pm 0.41$ & $>0.0500$ \\
\hline \multicolumn{6}{|l|}{ Vascular invasion } \\
\hline- & 33 & $0.69 \pm 0.86$ & & $0.42 \pm 0.86$ & \\
\hline+ & 18 & $0.73 \pm 0.83$ & 0.5957 & $0.56 \pm 0.83$ & 0.7227 \\
\hline \multicolumn{6}{|l|}{ Pleural invasion } \\
\hline- & 32 & $0.23 \pm 0.63$ & & $1.80 \pm 0.71$ & \\
\hline+ & 19 & $0.84 \pm 1.02$ & $0.0123^{\mathrm{a}}$ & $1.68 \pm 0.58$ & 0.5566 \\
\hline \multicolumn{6}{|l|}{ Tumor size } \\
\hline$\leq 30 \mathrm{~mm}$ & 33 & $0.30 \pm 0.64$ & & $1.76 \pm 0.66$ & \\
\hline$>30 \mathrm{~mm}$ & 18 & $0.82 \pm 1.07$ & $0.0363^{\mathrm{a}}$ & $1.77 \pm 0.66$ & 0.9184 \\
\hline \multicolumn{6}{|l|}{ Lymph node metastasis } \\
\hline- & 44 & $0.55 \pm 0.88$ & & $1.82 \pm 0.58$ & \\
\hline+ & 7 & $0.10 \pm 0.12$ & 0.1083 & $1.43 \pm 0.98$ & 0.1429 \\
\hline \multicolumn{6}{|l|}{ Stage } \\
\hline I & 43 & $0.56 \pm 0.88$ & & $1.81 \pm 0.59$ & \\
\hline II & 6 & $0.17 \pm 0.41$ & & $1.33 \pm 1.03$ & \\
\hline III & 2 & $0.50 \pm 0.71$ & $>0.0500$ & $2.00 \pm 0.00$ & $>0.0500$ \\
\hline \multicolumn{6}{|l|}{ Stromal change } \\
\hline Active fibrosis & 36 & $0.50 \pm 0.85$ & & $1.75 \pm 0.65$ & \\
\hline Sclerosis & 15 & $0.53 \pm 0.83$ & 0.8980 & $1.80 \pm 0.68$ & 0.8054 \\
\hline
\end{tabular}

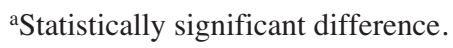

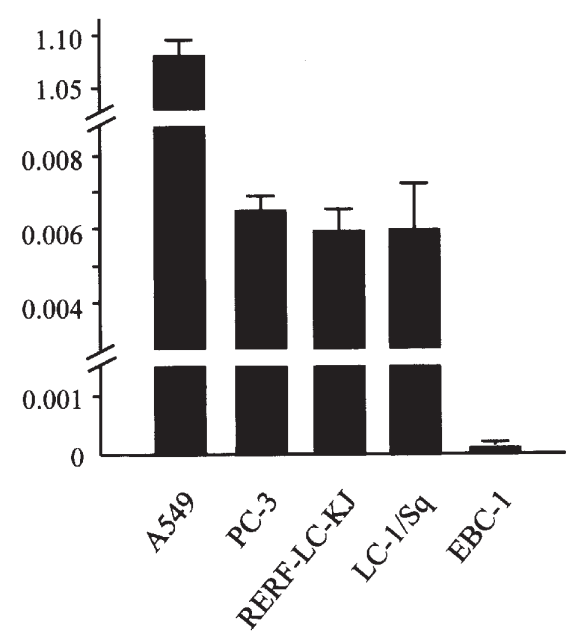

Figure 4. Quantitative real-time PCR analysis of lumican mRNA in lung cancer cell lines. Lumican mRNA was detected in all five lung cancer cell lines, and its expression level was highest in A549 cells and lowest in EBC-1. The lumican mRNA expression level in LC-1/Sq cells was 10,000-fold higher than that in EBC-1 cells.
Quantitative real-time PCR analysis. Lumican mRNA was detected in all ADC and SqCC cell lines examined, and its expression level was highest in A549 cells and lowest in EBC-1 cells (Fig. 4). The lumican mRNA expression level in A549 cells was 10,000-fold higher than that in EBC-1 cells.

Western blot analysis. Western blot analysis of the lumican protein extracted from $\mathrm{ADC}$ and $\mathrm{SqCC}$ cell lines showed that it was expressed in cancer cells (Fig. 5A, first to fifth lane from left). To examine whether lumican is effectively secreted to the extracellular space, culture medium was collected and analyzed by Western blot analysis. The lumican protein was also detected in the culture medium of ADC and SqCC cells (Fig. 5B, first to fifth lane from left). Various molecular weights of the lumican protein were detected ranging from 37 to $250 \mathrm{kDa}$ in the cells and culture medium. The molecular weight differed between lumican extracted from cells and that in culture medium. There was a significant difference in the molecular weight of lumican in culture medium between 


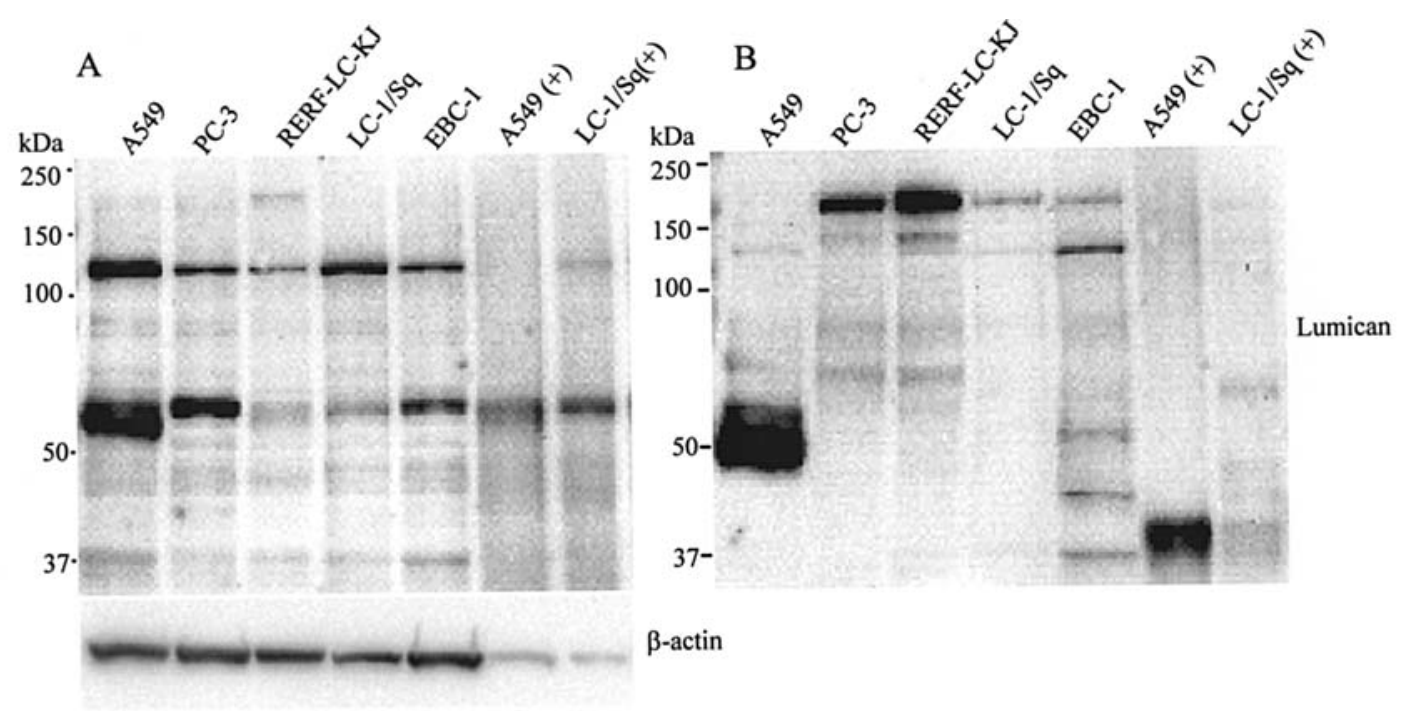

Figure 5. Western blot analysis of lumican in lung cancer cell lines. Both cell extracts (A) and culture medium (B) showed 37- to 250-kDa bands corresponding to lumican. A549 (+) and LC-1/Sq (+) lanes show that the lumican protein in cell extracts and that in culture medium were chemically digested, and the molecular weight of lumican was observed to decrease.

cell lines, but the molecular weights of lumican extracted from cells were nearly the same between cell lines.

To clarify the reason for the different molecular weights of lumican, chemical deglycosylation was performed using a GlycoProfile IV Kit, which can digest all types of glycan. In A549 and LC-1/Sq cells originating from ADC and SqCC, respectively, the lumican protein extracted from cells and that in culture medium were digested, and the molecular weight of lumican was observed to decrease (Fig. 5A and B, sixth and seventh lanes respectively, from the left).

\section{Discussion}

Lumican is a major proteoglycan in the lungs, but its role in normal lung tissue is not well understood (7,30-32). In this study, lumican was found to localize in collagen fibers and fibroblasts in peribronchial connective tissues, VSMCs and the bronchial epithelium of normal lungs. These findings agree with our previous reports that lumican localizes in the periductal connective tissues of normal pancreas $(11,18)$ and VSMCs $(8,10)$, and suggest that lumican assembles and organizes into collagen fibers around ductal tissues and in the media of arteries.

In lung SqCC and ADC, lumican was expressed in the cytoplasm of carcinoma cells and/or stromal tissues, which is in agreement with our previous reports of lumican expression in pancreatic $\operatorname{ADC}(12,18)$, colorectal $\operatorname{ADC}(14-16)$ and uterine cervical SqCC (17). In the present study, lumican expression correlated with various clinicopathological factors, such as keratinization and vascular invasion in lung SqCC, and pleural invasion and larger tumor size in lung ADC. These results suggest that lumican plays various roles in lung cancer and differential roles in lung SqCC and ADC.

The expression pattern of lumican differed between lung SqCC and ADC. SqCC showed higher lumican expression levels in cancer cells than in stromal tissues, whereas ADC showed higher lumican expression levels in stromal tissues than in cancer cells. The expression pattern of lumican suggests a difference in the role of lumican between lung SqCC and ADC.

Furthermore, lumican showed a difference in molecular weight between the cytoplasm and culture medium owing to glycosylation. Malignant transformation is associated with abnormal glycosylation, resulting in the expression of an altered glycosylation pattern (35). Abnormal glycosylation caused by alteration of glycosyltransferase, a catabolic enzyme, or a precursor carbohydrate chain, plays important roles in metastasis, invasion and attachment of cancer cells. The difference in glycosylation pattern between lumican in the cytoplasm and secreted lumican observed in the present study indicates the differential roles of lumican in lung cancer cells and stromal tissues.

A previous study showed that in uterine cervical SqCC, lumican is expressed in cancer cells, and is not expressed in squamous or ductal epithelial cells in noncancerous tissues (17). In the corneal squamous epithelium, lumican is expressed ectopically and transiently during the early phase of corneal wound healing (6). These findings, including those of our present study, indicate that lumican is not synthesized by normal squamous epithelial cells, but is ectopically synthesized by cancer cells and epithelial cells close to cancer cells.

The relationship between stromal lumican in lung SqCC and vascular invasion observed in this study is consistent with a previous report that lumican regulates angiogenesis via $\mathrm{p} 38$ MAPK in the vascular endothelium (36). Tumoral angiogenesis is important for tumor growth, invasion, metastasis, and the microenvironment $(27,37,38)$; therefore, further studies are needed to clarify the role of lumican.

In lung $\mathrm{ADC}$, lumican expression in the cytoplasm of cancer cells correlated with pleural invasion and larger tumor size. In advanced colorectal ADC, lumican expression tends to correlate with the depth of tumor invasion, and a high lumican expression level correlates with poor patient prognosis (14). These findings suggest that lumican in ADC promotes tumor progression and invasion. 
Fibrous tissues adjacent to cancer cells are often observed in non-small cell lung carcinoma $(20,25)$. In this study, to clarify the relationship between lumican and carcinomaassociated lung fibrosis, we divided the lung fibrosis pattern into active fibrosis and sclerosis. Almost all lung SqCC specimens showed the active fibrosis pattern, and ADC showed both the active fibrosis and sclerosis patterns. There was no significant difference between the fibrosis pattern and lumican expression.

In conclusion, lung SqCC and ADC expressed lumican in cancer cells and/or stromal tissues and showed differential expression patterns of lumican. Various types of lumican formed by glycosylation were observed in this study. The expression pattern of lumican and distinct glycosylation patterns of lumican in cells and stromal tissues play important roles in vascular invasion, differentiation, proliferation and invasion of lung SqCC and ADC cells.

\section{Acknowledgements}

The authors thank Ms. Yoko Kawamoto, Ms. Taeko Suzuki, Mr. Kiyoshi Teduka and Mr. Takenori Fujii (Department of Pathology, Integrative Oncological Pathology) for their excellent technical assistance, and Ms. Yuko Ono (Department of Pathology, Integrative Oncological Pathology) for preparing the manuscript. We also thank Dr Shin-ichi Tsuchiya (Division of Surgical Pathology) for preparing the tissue blocks. This work was supported by a Grant of the Faculty of Medicine, Kagawa University and Grants-in-Aid for Young Scientists from the Japan Society for the Promotion of Science to Y. Matsuda (B, no. 20790976) and T. Yamamoto (B, no. 20790974).

\section{References}

1. Iozzo RV: Matrix proteoglycans: from molecular design to cellular function. Annu Rev Biochem 67: 609-652, 1998.

2. Ishiwata T, Fujii T, Ishiwata S, Ikegawa S and Naito Z: Effect of morpholino antisense oligonucleotide against lumican mRNA in human embryonic kidney (HEK) 293 cells. Pathol Int 54: 77-81, 2004.

3. Naito Z: The role of small leucine-rich proteoglycan (SLRP) family in pathological lesions and cancer cell growth. J Nippon Med Sch 72: 137-145, 2005.

4. Saika S, Miyamoto T, Tanaka S, Tanaka T, Ishida I, Ohnishi Y, Ooshima A, Ishiwata T, Asano G, Chikama T, Shiraishi A, Liu CY, Kao CW and Kao WW: Response of lens epithelial cells to injury: role of lumican in epithelial-mesenchymal transition. Invest Ophthalmol Vis Sci 44: 2094-2102, 2003.

5. Austin BA, Coulon C, Liu CY, Kao WW and Rada JA: Altered collagen fibril formation in the sclera of lumican-deficient mice. Invest Ophthalmol Vis Sci 43: 1695-1701, 2002.

6. Cornuet PK, Blochberger TC and Hassell JR: Molecular polymorphism of lumican during corneal development. Invest Ophthalmol Vis Sci 35: 870-877, 1994.

7. Dolhnikoff M, Morin J, Roughley PJ and Ludwig MS: Expression of lumican in human lungs. Am J Respir Cell Mol Biol 19: 582-587, 1998.

8. Qin H, Ishiwata T and Asano G: Effects of the extracellular matrix on lumican expression in rat aortic smooth muscle cells in vitro. J Pathol 195: 604-608, 2001.

9. Baba H, Ishiwata T, Takashi E, Xu G and Asano G: Expression and localization of lumican in the ischemic and reperfused rat heart. Jpn Circ J 65: 445-450, 2001.

10. Onda M, Ishiwata T, Kawahara K, Wang R, Naito $Z$ and Sugisaki Y: Expression of lumican in thickened intima and smooth muscle cells in human coronary atherosclerosis. Exp Mol Pathol 72: 142-149, 2002.
11. Naito Z, Ishiwata T, Lu YP, Teduka K, Fujii T, Kawahara K and Sugisaki Y: Transient and ectopic expression of lumican by acinar cells in L-arginine-induced acute pancreatitis. Exp Mol Pathol 74: 33-39, 2003.

12. Ping LY, Ishiwata T and Asano G: Lumican expression in alpha cells of islets in pancreas and pancreatic cancer cells. J Pathol 196: 324-330, 2002.

13. Troup S, Njue C, Kliewer EV, Parisien M, Roskelley C, Chakravarti S, Roughley PJ, Murphy LC and Watson PH: Reduced expression of the small leucine-rich proteoglycans, lumican, and decorin is associated with poor outcome in nodenegative invasive breast cancer. Clin Cancer Res 9: 207-214, 2003.

14. Seya T, Tanaka N, Shinji S, Yokoi K, Koizumi M, Teranishi N, Yamashita K, Tajiri T, Ishiwata T and Naito Z: Lumican expression in advanced colorectal cancer with nodal metastasis correlates with poor prognosis. Oncol Rep 16: 1225-1230, 2006.

15. Shinji S, Tajiri T, Ishiwata T, Seya T, Tanaka N and Naito Z: Different expression levels of lumican in human carcinoid tumor and neuroendocrine cell carcinoma. Int J Oncol 26: 873-880, 2005.

16. Lu YP, Ishiwata T, Kawahara K, Watanabe M, Naito Z, Moriyama Y, Sugisaki Y and Asano G: Expression of lumican in human colorectal cancer cells. Pathol Int 52: 519-526, 2002.

17. Naito Z, Ishiwata T, Kurban G, Teduka K, Kawamoto $Y$, Kawahara K and Sugisaki Y: Expression and accumulation of lumican protein in uterine cervical cancer cells at the periphery of cancer nests. Int J Oncol 20: 943-948, 2002.

18. Ishiwata T, Cho K, Kawahara K, Yamamoto T, Fujiwara Y, Uchida E, Tajiri T and Naito Z: Role of lumican in cancer cells and adjacent stromal tissues in human pancreatic cancer. Oncol Rep 18: 537-543, 2007.

19. Kusafuka K, Ishiwata T, Sugisaki Y, Takemura T, Kusafuka M, Hisha $\mathrm{H}$ and Ikehara S: Lumican expression is associated with the formation of mesenchyme-like elements in salivary pleomorphic adenomas. J Pathol 203: 953-960, 2004.

20. Noguchi M, Morikawa A, Kawasaki M, Matsuno Y, Yamada T, Hirohashi S, Kondo H and Shimosato Y: Small adenocarcinoma of the lung. Histologic characteristics and prognosis. Cancer 75: 2844-2852, 1995

21. Maeshima AM, Niki T, Maeshima A, Yamada T, Kondo H and Matsuno Y: Modified scar grade: a prognostic indicator in small peripheral lung adenocarcinoma. Cancer 95: 2546-2554, 2002.

22. Fukushima M, Fukuda Y, Kawamoto M and Yamanaka N: Elastosis in lung carcinoma: Immunohistochemical, ultrastructural and clinical studies. Pathol Int 50: 1004-1013, 2000.

23. Okudera K, Kamata Y, Takanashi S, Hasegawa Y, Tsushima T, Ogura Y, Nakanishi K, Sato H and Okumura K: Small adenocarcinoma of the lung: prognostic significance of central fibrosis chiefly because of its association with angiogenesis and lymphangiogenesis. Pathol Int 56: 494-502, 2006.

24. Shimosato Y, Suzuki A, Hashimoto T, Nishiwaki Y, Kodama T, Yoneyama T and Kameya T: Prognostic implications of fibrotic focus (scar) in small peripheral lung cancers. Am J Surg Pathol 4: 365-373, 1980

25. Funai K, Yokose T, Ishii G, Araki K, Yoshida J, Nishimura M, Nagai K, Nishiwaki Y and Ochiai A: Clinicopathologic characteristics of peripheral squamous cell carcinoma of the lung. Am J Surg Pathol 27: 978-984, 2003.

26. Maeshima AM, Maeshima A, Asamura $\mathrm{H}$ and Matsuno Y: Histologic prognostic factors for small-sized squamous cell carcinomas of the peripheral lung. Lung Cancer 52: 53-58, 2006.

27. Kenny PA, Lee GY and Bissell MJ: Targeting the tumor microenvironment. Front Biosci 12: 3468-3474, 2007.

28. Matsui K, Kitagawa M, Sugiyama S and Yamamoto K: Distribution pattern of the basement membrane components is one of the significant prognostic correlates in peripheral lung adenocarcinomas. Hum Pathol 26: 186-194, 1995.

29. Eto T, Suzuki H, Honda A and Nagashima Y: The changes of the stromal elastotic framework in the growth of peripheral lung adenocarcinomas. Cancer 77: 646-656, 1996.

30. De Medeiros Matsushita M, da Silva LF, dos Santos MA, Fernezlian S, Schrumpf JA, Roughley P, Hiemstra PS, Saldiva PH, Mauad T and Dolhnikoff M: Airway proteoglycans are differentially altered in fatal asthma. J Pathol 207: 102-110, 2005.

31. Pini L, Hamid Q, Shannon J, Lemelin L, Olivenstein R, Ernst P, Lemiere C, Martin JG and Ludwig MS: Differences in proteoglycan deposition in the airways of moderate and severe asthmatics. Eur Respir J 29: 71-77, 2007. 
32. Okano T, Kondo T, Kakisaka T, Fujii K, Yamada M, Kato H, Nishimura T, Gemma A, Kudoh S and Hirohashi S: Plasma proteomics of lung cancer by a linkage of multi-dimensional liquid chromatography and two-dimensional difference gel electrophoresis. Proteomics 6: 3938-3948, 2006.

33. Travis WD, Brambilla E, Muller-Hermelink HK and Harris CC: World Health Organization Classification of Tumors. Pathology and Genetics of Tumors of the Lung, Pleura, Thymus and Heart. IARCPress, Lyon, 2004.

34. Matsuda Y, Yamakawa K, Saoo K, Hosokawa K, Yokohira M, Kuno T, Iwai J, Shirai T, Obika K, Kamataki T and Imaida K: CYP2A6 overexpression in human lung cancers correlates with a high malignant status. Oncol Rep 18: 53-57, 2007.
35. Kannagi R, Izawa M, Koike T, Miyazaki K and Kimura N Carbohydrate-mediated cell adhesion in cancer metastasis and angiogenesis. Cancer Sci 95: 377-384, 2004.

36. Albig AR, Roy TG, Becenti DJ and Schiemann WP: Transcriptome analysis of endothelial cell gene expression induced by growth on matrigel matrices: identification and characterization of MAGP-2 and lumican as novel regulators of angiogenesis. Angiogenesis 10: 197-216, 2007.

37. Khosravi Shahi P and Fernandez Pineda I: Tumoral angiogenesis: review of the literature. Cancer Invest 26: 104-108, 2008.

38. Sun S and Schiller JH: Angiogenesis inhibitors in the treatment of lung cancer. Crit Rev Oncol Hematol 62: 93-104, 2007. 